\title{
APRENDENDO COM VIDEOGAMES: UMA INVESTIGAÇÃO SOBRE LETRAMENTOS, LÍNGUA INGLESA E EXPERIÊNCIAS DISPONÍVEIS EM UM JOGO DE SIMULAÇÃO
}

\author{
LEARNING FROM VIDEOGAMES: AN INVESTIGATION \\ ON LITERACY, ENGLISH LANGUAGE AND AVAILABLE \\ EXPERIENCES IN A SIMULATION GAME
}

\author{
Bárbara Cristina Gallardo 1 \\ Universidade do Estado de Mato Grosso \\ Edina Flores Parada ${ }^{2}$ \\ Universidade do Estado de Mato Grosso \\ Geovane Aparecido Martins ${ }^{3}$ \\ Universidade do Estado de Mato Grosso
}

Resumo: Neste estudo, investigamos as estratégias de compreensão da língua inglesa, utilizadas para se jogar o videogame Power \& Revolution: Geopolitical Simulator 4, os aspectos motivacionais desse jogo e as contribuições potenciais para o ensino formal. Embasamo-nos, principalmente, nas discussões sobre letramentos digitais, novos letramentos, gamificação, discurso e motivação. Trata-se de um estudo de caso de abordagem qualitativa, cujos instrumentos de coleta foram uma entrevista e a observação do funcionamento do videogame. Os resultados indicaram que o inglês serviu como mediador para o alcance de um objetivo. $O$ aspecto lúdico e a experiência corporificada foram os fatores que motivaram o jogador, além do interesse por temas do mundo físico. Identificamos o potencial desse videogame para fomentar discussões sobre ética, cidadania e modos de se posicionar nos contextos on e offline.

Palavras-Chave: Letramento digital; Gamificação; Educação.

\footnotetext{
Endereço eletrônico: barbarag@unemat.br.

2 Endereço eletrônico: edinafd@outlook.com.

3 Endereço eletrônico: geovane-martins@hotmail.com.
} 
Abstract: In this study, we investigated the strategies for understanding the English language used to play the video game Power \& Revolution: Geopolitical Simulator 4, the motivational aspects of this game and the potential contributions to formal education. Discussions were based, mainly, on digital literacies studies, new literacies, gamification, discourse and motivation. This is a case study done through qualitative research which used as data collection an interview and observation of how the video game works. The results indicated that English served as a medium to achieve a goal. The playful aspect and the embodied experience were the factors that motivated the player, in addition to issues related to the physical world. We identified the potential of this video game to foster discussions on ethics, citizenship and ways of positioning oneself in on and offline contexts.

Keywords: Digital literacy; Gamification; Education.

\section{INTRODUÇÃO}

Ao mesmo tempo em que a internet apresenta riscos, desde a estabilidade de democracias à autoestima das pessoas, por meio da disseminação de informações falsas e mensagens de ódio, ela representa uma possibilidade riquíssima de ensino e aprendizagem, diferente do modelo da escola. As pesquisas de Gee $(2003,2004)$ sobre videogames, por exemplo, constatam que modelos tradicionais de aprendizagem raramente conseguem acompanhar as práticas digitais oferecidas nos ambientes online. Como professores, diante do cenário mundial atual, estabelecido na fluidez do físico-virtual (CASTELLS, 2001), temos o desafio de integrar as práticas digitais às nossas práticas analógicas, de modo seletivo e criativo. Talvez, a escolarização das práticas cotidianas de crianças e adolescentes não seja o único caminho para alcançar os objetivos de um ensino-aprendizado bem-sucedido. A compreensão de como essas práticas acontecem pode nos despertar para diferentes possibilidades, à medida que nos dispusermos a conhecer melhor os contextos por onde circulam o nosso público.

A motivação para a escrita deste artigo surgiu a partir da constatação de que os adolescentes que temos contato passam muito mais tempo sozinhos, com seus computadores conectados à internet, participando de práticas online, do que 
com a família ou amigos. Pode-se dizer que em muitos desses casos o computador tornou-se uma extensão de seus corpos, moldando, assim, suas vidas e identidades, no entrelace físico-virtual (CASTELLS, 2001).

Segundo Barton e Lee (2015), a tecnologia faz parte do conhecimento adquirido através da prática vivenciada pelas pessoas em todas as circunstâncias, modos ou situações, na interação nas redes sociais com amigos, família, trabalho e estudo. Esses autores advogam que a tecnologia muda constantemente o cotidiano das pessoas que, aos poucos, vão percebendo essas mudanças e considerando-as normais. Não é mais admitido, por exemplo, um trabalho escolar manuscrito, como acontecia antes da popularização dos computadores. Outro exemplo são as pesquisas, escolares e não escolares, que antes eram feitas em enciclopédias. Atualmente, é natural ${ }^{4}$ que sejam feitas nos buscadores conectados à internet ${ }^{5}$.

Por esses motivos, elaboramos este estudo com o objetivo de investigar uma prática digital entre os adolescentes que conhecemos: os letramentos acionados nas práticas do videogame Power E Revolution: Geopolitical Simulator 4. Na posição de professores de inglês, delimitamos os objetivos deste estudo, propondo-nos a investigar: i) o funcionamento da língua inglesa como meio de aprendizado para se avançar etapas desse videogame, popular entre os adolescentes no Brasil atualmente, e que não possui versão em português ${ }^{6}$; ii) as características do jogo que motivaram a sua escolha; iii) os modos pelos quais a

\footnotetext{
4 É natural para as pessoas que têm acesso à internet. No entanto, influencia a vida dos que não têm acesso, porque a sociedade passa a se organizar, naturalmente, em torno das práticas digitais, como se todos fizessem parte dessa realidade.

5 Um exemplo de 'normalidade' que se mostrou equivocado foi a premissa de que a internet estava, razoavelmente, disponível para um grande número de estudantes das escolas do Brasil, no ano de 2020. Em tempos de pandemia causado pelo COVID-19, o ensino remoto emergencial foi pensado para a retomada das aulas nas escolas formais, depois de uma suspensão temporária para evitar a propagação do vírus. Revelou-se, então, que muitos estudantes não tinham acesso à internet como parte de sua rotina e, ainda, que muitos não tinham sequer computador ou smartphones.

6 Pelo menos não existia até a data de término deste estudo, dia 20/04/2020.
} 
escola pode incluir o universo dos videogames em sua pauta de discussão, sem necessariamente escolarizá-los. Os seguintes questionamentos guiaram a pesquisa: em que medida os videogames podem contribuir para o aprendizado de inglês? Em que medida os videogames podem contribuir para a educação formal?

Acreditamos que a reflexão sobre os resultados dessas questões pode desestabilizar planejamentos fechados de curso e fomentar uma reflexão sobre práticas que aproximem o ensino formal das práticas não escolares de muitos estudantes, além de somar possibilidades de aprender e ensinar para todos, estudantes e professores.

Este artigo tem quatro seções, além da introdução e das considerações finais. A seguir, apresentamos uma breve discussão sobre os letramentos digitais e os novos letramentos, pertinentes aos propósitos da análise dos dados. $\mathrm{Na}$ segunda seção, discorremos sobre a origem do termo gamificação, seus objetivos iniciais e contribuições para o aprendizado, de acordo com as tendências de ensino-aprendizado neste século. Na terceira seção, explicamos, brevemente, a metodologia utilizada neste estudo, e na quarta descrevemos e analisamos os dados.

\section{LETRAMENTOS DIGITAIS, NOVOS LETRAMENTOS E OS DESAFIOS DA ESCOLA}

Diante dos desdobramentos da globalização contemporânea e do advento da internet no século XXI, governos, ministérios da educação, empregadores e pesquisadores buscam ações que incentivem os sujeitos, a promoção de habilidades próprias e a capacidade de resolução de problemas, em um regime de colaboração e trabalho em equipe, autonomia e flexibilidade, criatividade e inovação, pensamento crítico e aprendizagem permanente. Para alcançar esses objetivos, Dudeney, Hockly e Pegrum (2016, p. 17) ponderam que: 
(...) No centro desse complexo de habilidades, está a capacidade de se envolver com as tecnologias digitais, algo que exige um domínio dos letramentos digitais necessários para usar eficientemente essas tecnologias, para localizar recursos, comunicar ideias e construir colaborações que ultrapassem os limites pessoais, sociais, econômicos, políticos e culturais.

Esses autores definem os letramentos digitais como "habilidades individuais e sociais necessárias para interpretar, administrar, compartilhar e criar sentido eficazmente no âmbito crescente dos canais de comunicação digital" (DUDENEY; HOCKLY; PEGRUM, 2016, p. 17). Baseados nos postulados de Pegrum (2009; 2011), Dudeney et al. (2016, p. 20- 21) dividem os letramentos em "quatro pontos centrais - linguagem [por exemplo, o hipertexto], informação [letramento em pesquisa, etc], conexões [letramento intercultural, etc.] e (re)desenho [letramento remix]", e destacam a figura do professor como responsável em auxiliar os alunos no desenvolvimento de estratégias que garantam o domínio de tais letramentos.

Na relação entre o sujeito e as práticas digitais, Buzato (2006, p. 01) concebe as novas tecnologias como "oportunidades para melhorar o mundo", não como uma variável autônoma7 , capaz de gerar resultados por si só, mas como fruto de uma ação coletiva entre humanos e não humanos (computadores, smartphones, etc.), que molda, ao mesmo tempo em que é moldada por essa relação. Xavier (2011) destaca as habilidades específicas de leitura e escrita dos códigos e sinais verbais e não-verbais da tecnologia digital, necessárias para uma participação bem-sucedida nos contextos digitais. Entendemos, a partir das discussões de Buzato (2006) e Xavier (2011), que a apropriação de determinados letramentos digitais propicia uma interação significativa entre o sujeito e as práticas digitais

\footnotetext{
7 Buzato (2006) discute a relação entre tecnologia e sociedade a partir dos postulados de Warschauer (2003), que identifica três tipos de discursos sobre a tecnologia: os deterministas, os neutralistas e os que concebem o desenvolvimento tecnológico a partir da interação entre sujeitos e tecnologia.
} 
que ampliam as habilidades e competências desse sujeito e exigem diferentes reflexões, em comparação com os letramentos analógicos.

Assim, podemos dizer que enquanto Dudeney et al. (2016, p. 20) enfatizam o uso eficiente da tecnologia para fazer coisas (localizar, construir) para uma "plena participação no mundo além da sala de aula", Xavier e Buzato destacam a capacidade de atribuir sentidos às práticas de leitura e escrita digitais. Tais visões nos fazem sugerir uma comparação com as diferenças entre alfabetização e letramento ${ }^{8}$, amplamente discutidas no contexto analógico. Para o professor, a incorporação da concepção de letramentos que vai além do 'fazer ações', mas 'fazer sentido das ações realizadas' é valiosa, no sentido de propor modos de refletir e analisar criticamente o que está diante dos olhos, tendo em vista a multimodalidade dos textos e os multiletramentos requeridos nas práticas contemporâneas de ensino e de vida. Sobre esse assunto Buzato (2006, p. 06) observa que

(...) Obviamente todo letramento é funcional em algum sentido específico, mas não se restringe ao cumprimento de uma demanda social externa: um letramento é uma forma de agir, afirmar-se, construir e sustentar uma visão de mundo partilhada por um grupo e, portanto, carrega traços identitários e significados compartilhados por esse grupo.

O aspecto funcional e a capacidade crítica tornam o letrado digital algo complexo de se determinar, na perspectiva de Smith (2000 apud SOUZA, 2007), que sugere que o domínio de ambas habilidades equivale ao domínio de um novo tipo de discurso que, muitas vezes, corresponde ao aprendizado de uma outra língua. Esta é uma interessante analogia, se pensarmos que, muitas vezes, uma língua estrangeira é ensinada por meio de uma abordagem funcional, não discursiva. Nesse caso, essa analogia corresponderia a aprender a usar um

\footnotetext{
8 Alfabetização como o domínio de habilidades básicas para codificar e decodificar a escrita e, letramento como habilidades intelectuais acionadas em práticas sociais e culturais que garantem uma participação efetiva dos usuários nos contextos que circula (BARTON, 1994).
} 
computador (ligar, desligar, imprimir, postar fotos em uma rede social, escrever um e-mail, etc.), sem necessariamente se refletir sobre os aspectos críticos envolvidos, por exemplo, no compartilhamento de determinadas informações, na função dos cookies $^{9}$ cada vez que se visita uma página e nos anúncios direcionados, divulgados em determinados perfis de redes sociais. Podemos dizer que o conhecimento funcional corresponderia à visão de 'fazer ações', enquanto o viés discursivo corresponderia aos letramentos no sentido de 'atribuir significado'.

Entendemos que a relação e as práticas nos contextos on e offline estão incorporadas no cotidiano dos usuários da internet e que essas práticas são responsáveis pela construção de conhecimento, que difere da construção do modo analógico. Assim, compartilhamos com Buzato (2009, p. 22) a definição de letramentos digitais como "redes complexas e heterogêneas que conectam letramentos (práticas sociais), textos, sujeitos, meios e habilidades que se agenciam, entrelaçam, contestam e modificam mútua e continuamente, por meio, virtude ou influência das $\mathrm{TIC}^{10^{\prime \prime}}$. Buzato advoga que a participação nas práticas no meio digital e físico mudam e provocam mudanças, em uma relação contínua, no modo como lidam com a nova configuração espaço-temporal e com as relações com a informação. Por esse viés, estar atento às constantes (re)configurações que acontecem na imbricação de contextos pode ser, na atualidade, uma das chaves para a conexão entre aprendizes e escola.

Sobre os novos letramentos, Barton e Lee (2015) fazem uma diferenciação entre os diversos letramentos disponíveis para a leitura e escrita das mídias, os quais eles chamam de 'novos', e os letramentos digitais mais presos aos modelos

\footnotetext{
9 Cookies são arquivos que se instalam no computador quando se visita um site. Eles armazenam desde as preferências dos usuários até seu e-mail e senha. Está relacionado, portanto, a questões de privacidade e segurança. Disponível em: $<$ https://seguranca.uol.com.br/antivirus/dicas/curiosidades/o-que-sao-cookies-e-como-elespodem-me-prejudicar.html\#rmcl>.

10 Tecnologias de Informação e Comunicação (TIC).
} 
tradicionais de leitura e escrita que foram meramente transferidos para a leitura e escrita na tela:

[...] "novos letramentos (pelas novas mídias)" e "novos letramentos vernaculares", estamos nos referindo de modo geral às atividades cotidianas de ler e escrever online. Preferimos o termo plural "letramentos" para capturar o fato de que o letramento não se baseia em habilidades, mas que há muitos tipos diferentes de letramento utilizados pelas pessoas para diferentes fins. (BARTON; LEE, 2015, p. 20)

Trata-se, segundo nossa compreensão, de uma visão técnica dos (novos) letramentos, quando a comparamos com a definição postulada por Lankshear e Knobel (2007), que propõem um novo ethos na definição dos 'novos letramentos', relacionado a um novo modo de lidar com o conhecimento e a informação, e, assim, uma visão que vai além do ler e escrever, mas no modo de conceber práticas e modelos de pensamento que foram consolidados na era industrial e que sofreram movimentos causados pelas novas práticas e modos de lidar com as tecnologias, movimentos que provocaram mudanças de perspectivas consolidadas até então. Difere, também, da concepção de Buzato, apresentada previamente, que concebe os letramentos digitais como entrelaçados e se modificando mutuamente.

A maioria das práticas digitais é mediada por textos, conforme advogam Barton e Lee (2015), sendo a produção e utilização de textos online práticas que ocupam grande parte da vida das pessoas. Uma série de estudos destaca a dimensão textual dos letramentos digitais em diversas plataformas, dentre elas, salas de bate-papo, mensagens instantâneas, espaços de criação de fanfictions, videogames, entre outros (BARTON; LEE, 2015). Para alcançar os objetivos deste estudo, consideramos a hipermodalidade dos textos nos videogames (LEMKE, 2002; MAGNANI, 2008), tendo em vista a análise dessa característica no videogame Power $\mathcal{E}$ Revolution: Geopolitical Simulator 4 e na investigação das 
práticas de um adolescente, expressas em uma entrevista; ou seja, na análise da construção de sentidos que ele faz sobre essa experiência.

A origem do termo "gamificação" e algumas de suas características é o tema da seção seguinte.

\section{UM BREVE HISTÓRICO SOBRE A GAMIFICAÇÃO}

O termo "gamificação" não é exclusivo da área da educação. Pelo contrário, surgiu na indústria da mídia digital para ser usado em contextos não relacionados a jogos, para motivar e aumentar a atividade em diversos setores, desde finanças, saúde, educação e sustentabilidade até a mídia de notícias e entretenimento. Deterding et al. (2012, p. 10) definem gamificação como “o uso de elementos de design de jogo em contextos fora do jogo ${ }^{11 "}$. Como os videogames são projetados para entretenimento, a ideia era a de que suas características poderiam motivar as pessoas a se envolverem com empresas e produtos e, assim, tornar os serviços mais agradáveis. Apesar deste termo só ter sido usado no século XXI, o conceito de gamificação já estava presente nos trabalhos de Malone, nos anos 1980, voltados a projetos de interfaces agradáveis, com base nos videogames. Outros autores nesse período também produziram estudos direcionados à relação entre trabalho e entretenimento, com o objetivo de tornar a rotina de trabalho mais interessante (DETERDING et al., 2012).

Os elementos usados na gamificação são escores, troféus e quadros de liderança, que, em inglês, são conhecidos como PBL (Points, Badges e Leaderboards) (LEFFA, 2020). Dentre as plataformas que usam os PBL estão a Wikipedia, o Duolingo, o eBay, a Amazon, a TripAdvisor e o Google News. Por serem multifacetados, os PBL são usados em diferentes domínios e para diferentes fins (BORNFELD; RAFAELI, 2017).

11 No original: "The use of game design elements in non-game contexts". 
Com base na discussão de Hamari (2013), Bornfeld e Rafaeli (2017) definem a gamificação como "um processo de aprimoramento de serviços com recursos motivacionais para invocar experiências lúdicas e mais resultados comportamentais ${ }^{12 "}$. Este autor propõe a gamificação como "uma tentativa de converter serviços utilitários [para serem] mais prazerosamente orientados ${ }^{13 \prime \prime}$.

Antin e Churchill (2011 apud BORNFELD; RAFAELI, 2017) sugerem cinco funções principais dos troféus: definição de metas, instrução, reputação, status/afirmação e identificação de grupo. Algumas funções são de nível pessoal, como por exemplo: a definição e alcance de metas; outras estão relacionadas ao contexto social, por exemplo, o status e a reputação.

No uso da gamificação como estratégia, os elementos do jogo normalmente ficam visíveis para as outras pessoas, o que faz com que elas se comparem umas com as outras, fato que as motiva a alcançar melhores resultados $^{14}$. Uma das teorias usadas para fundamentar o uso da gamificação em alguns setores é a teoria da comparação (FESTINGER, 1954), relacionada ao comportamento e que parte do pressuposto de que as pessoas têm necessidade de avaliar suas habilidades e opiniões (BORNFELD; RAFAELI, 2017).

Na área da educação, Gee (2009) destaca os benefícios dos videogames para o aprendizado e baseia-se em estudos da ciência cognitiva para propor que os agentes aprenderão com mais facilidade, pela diversão que os jogos propiciam. Conforme esse autor, “os bons jogos de vídeo incorporam bons princípios de aprendizagem [...]. A um grau mais profundo do desafio e aprendizagem, são os responsáveis em tornar os bons jogos de vídeo motivadores e divertidos" (GEE, 2009, p. 3).

\footnotetext{
12 No original: "A process of enhancing services with motivational affordances in order to invoke gameful experiences and further behavioral outcomes".

13 No original: "An attempt to convert utilitarian services [to be] more hedonically oriented".

14 Em estabelecimentos comerciais, tais como o McDonald's, a exposição do retrato do funcionário do mês, por exemplo.
} 
Prensky (2004, p. 04) é otimista quanto aos resultados do aprendizado e da motivação na escola, quando as atividades são baseadas nas características dos videogames. "A tomada de decisão rápida e contínua, bom ritmo, a alta complexidade, objetivos claros de curto, médio e longo prazo, feedback imediato e descrição contínua e atualizada de performance ${ }^{15 "}$ são algumas características destacadas por este autor.

No Brasil, há uma série de pesquisas e trabalhos acadêmicos desenvolvidos e em andamento, baseados nos princípios da gamificação. Por exemplo, Leffa (2020) investigou a influência da gamificação no ensinoaprendizado de língua inglesa, tendo em vista o interesse de professores no uso dos jogos digitais para o aprendizado, seja de forma direta ou indireta. Com atividades propostas em forma de games em um ambiente virtual, o estudo revelou que os elementos da gamificação ficaram em terceiro lugar no quesito motivação, atrás dos quesitos 'conteúdo' e 'design didático' da atividade. Outras pesquisas no Brasil sobre videogames e ensino que merecem destaque estão reunidas no volume 4 (2019), da revista Linguagem \& Ensino ${ }^{16}$.

Baseado em estudos na área da ciência cognitiva, Gee (2009) argumenta que os videogames incorporam bons princípios de aprendizagem, pois estes integram todo um conjunto de princípios essencialmente sólidos, como por exemplo, o pensamento sistemático e estratégias para formulação de hipóteses. Esses princípios podem ser aplicados em outros cenários, tais como, o ensino das ciências nas escolas e, conforme os estudos sobre linguagem e gamificação têm evidenciado, no ensino de línguas também. Gee chama a atenção para as experiências corporificadas proporcionadas pelos videogames que superam as

15 No original: “(...) quick, continuous decision making, good pacing, high complexity, clear short, medium and long-term goals, immediate feedback, and adopting on the fly to the players' performance".

16 Disponível em: <https://periodicos.ufpel.edu.br/ojs2/index.php/rle/article/view/17766>. 
limitações do ensino passivo, envolvem e motivam o jogador de uma maneira diferente da experiência de ler uma história ou assistir a um filme.

Com base nas seções discutidas até aqui, a seguir apresentamos a metodologia utilizada na abordagem dos dados, seguida da análise e discussão dos dados.

\section{METODOLOGIA}

Este estudo se caracteriza como uma introdução a um estudo de caso de base qualitativa. $\mathrm{O}$ estudo de caso se concentra na investigação de um caso particular, um fenômeno contemporâneo, que representa um conjunto de casos semelhantes. Tem como objetivo explorar, descrever e explicar um evento, de modo a fundamentar uma generalização para situações similares. É um método apropriado quando a pesquisa busca responder questões sobre algum fenômeno social ou estudar o funcionamento de um fenômeno social (SEVERINO, 2007; YIN, 2010). Na pesquisa qualitativa, o pesquisador busca entender o significado que as pessoas dão aos fenômenos, conferindo, assim, ao estudo, uma visão interpretativa do mundo (DENZIN; LINCOLN, 2006). Pela brevidade do corpus coletado na entrevista, concebemos os resultados deste estudo como preliminares para guiar as próximas etapas da investigação sobre o objeto proposto.

Analisamos as possibilidades de aprendizado de inglês e a motivação para jogar o videogame Power E Revolution: Geopolitical Simulator 4. Escolhemos este jogo devido a sua popularidade entre os adolescentes que conhecíamos. Nos interessou, também, o fato de não haver uma versão em português, sendo necessária a habilidade de compreensão em inglês. Fizemos uma pesquisa sobre as características deste jogo e uma entrevista com um jogador, via WhatsApp. O 
participante tinha 13 anos na época da pesquisa e cursava o $8^{\circ}$ ano do ensino fundamental. Era filho de uma amiga de um dos autores deste $\operatorname{artigo}^{17}$.

\section{$4 \quad$ ANÁLISE E DISCUSSÃO DOS DADOS}

A fim de situar os dados e a discussão adiante, iniciamos esta seção com a apresentação das características do videogame analisado.

\subsection{Power E Revolution: Geopolitical Simulator 4}

O Power E Revolution: Geopolitical Simulator 4 é um videogame de estratégias que proporciona aos jogadores oportunidades de vivenciar práticas de letramentos diversas, tendo a língua inglesa como um meio de instrução. Destacam-se as características hipertextuais deste jogo que exige a habilidade do jogador para compreender o emprego de imagens, sons e a não linearidade dos espaços que percorre para conseguir alcançar seus objetivos. Estes têm que ser repensados constantemente, de acordo com os resultados de cada decisão.

Um dos sites que disponibiliza esse videogame, o descreve do seguinte modo:

[...] é uma simulação do nosso mundo atual, recriando suas características em profundidade e em vários domínios: econômico, político, militar, social, financeiro, ambiental, energético, transporte... [...] O jogo combina as fases da economia, comércio, wargames, construção, espionagem, simulação, e influência política e manipulação. Os jogadores podem optar pela gestão de um país ou vários ao mesmo tempo e projetar estratégias colaborativas para mudar o destino do mundo $[\ldots]^{18}$.

17 O termo de consentimento para a realização deste estudo foi assinado pela responsável do jogador entrevistado. Antes da entrevista, encontramos com a mãe do participante e explicamos os objetivos do estudo. Após o seu consentimento, conversamos pessoalmente com o participante e perguntamos se ele concordava em responder algumas perguntas sobre um dos videogames que jogava. Ele concordou e nos enviou o seu número de celular para que fizéssemos contato via WhatsApp.

18 Disponível em: <http://www.power-and-revolution.com/presentation.php?langue=pt $>$. 
O jogador é colocado sob várias condições desafiadoras, tendo que executar missões, concluir objetivos, tomar decisões importantes de ordem política, ambiental e social, estimulando, dessa forma, o pensamento estratégico. O jogo oferece duas opções ao participante: ele pode ser um chefe de estado ou um líder de oposição política. A escolha do cargo aponta as funções de cada jogador. Entre as funções de um chefe de estado estão modificar impostos, estabelecer salários mínimos, regular poderes dos partidos políticos e sindicatos, adicionar ou remover o serviço militar e gerir o orçamento do estado. As funções de um líder de oposição incluem dar instruções de voto em relação a projetos de lei, enviar militantes para protestar nas ruas, gerir orçamento de campanha, tentar conquistar figuras influentes, lançar protestos pacíficos, dentre outras. A dinamicidade dos acontecimentos a cada ação tomada motiva e exige a atenção do jogador, pois o coloca sob responsabilidades cruciais que podem facilitar ou dificultar as próximas etapas.

Essa descrição expõe exigências que vão além do uso de estratégias de compreensão oral da língua inglesa ${ }^{19}$, mas de oportunidades de experimentação corporificada (GEE, 2003) de conhecimento de mundo de cunho social, cultural, político, geográfico, histórico, econômico, militar, sobre o meio ambiente e transporte, além dos letramentos digitais exigidos pelo jogo. Dentre os princípios que Gee (2003) registra sobre experiências corporificadas de bons videogames que extrapolam as experiências inertes do aprendizado na escola, está o princípio da aprendizagem comprometida, caracterizada pela participação dos jogadores ${ }^{20}$ em um "envolvimento estendido (muito esforço e prática) como extensões de

19 Este é mais um dos desafios do jogo para os jogadores cuja língua materna não é o inglês. Não foi programado pelos designers do Geopolitical Simulator 4, mas segundo nossa compreensão funciona como um estímulo indireto para o aprendizado da língua.

20 No original, Gee chama de alunos os sujeitos que jogam, porque está comparando as experiências de aprendizado que acontecem na escola e no ato de jogar bons videogames. 
suas identidades do mundo real, em relação a uma identidade virtual com a qual sentem algum compromisso, e um mundo virtual que consideram atraente" (GEE, 2003, p. 67).

São experiências que provocam sensações que nós, professores e autores deste artigo, não conseguimos dimensionar, uma vez que tivemos dificuldades já de início para encontrar o videogame online e gratuito, conforme os jogadores que conhecíamos tinham nos orientado a fazer. Após compreendermos o funcionamento do Geopolitical Simulator 4, fizemos a entrevista com o participante, a qual descrevemos adiante.

\subsection{Entrevista}

A entrevista está dividida em quatro partes, as quais recortamos e nomeamos Diálogos 1, 2, 3 e 4. O diálogo 1 mostra o pronto atendimento do participante à nossa solicitação, conforme registrado a seguir:

\section{Diálogo 1: 01/10/201921}

[Pesquisador]: Olá, Jonas, boa noite. Tudo bem?

[Participante]: Olá?

[PE]: Sou Bruna, aluna da professora Taís. Acredito que ela já lhe fez alguns questionamentos sobre o jogo Geopolitical Stimulator ...

[PA]: Sim

[PE]: Que bom, posso lhe fazer algumas perguntas a respeito e você me responde

de maneira que seja mais confortável?

[PA]: Claro

Nesse primeiro contato, percebemos a disponibilidade do participante em falar sobre algo complexo e que exige o domínio de uma prática digital específica.

No diálogo 2, o participante relata como teve acesso ao videogame, demonstrando, assim, outro letramento digital: o de selecionar conteúdo

21 A entrevista aconteceu em um único dia. Os nomes de pesquisador e participante são fictícios. 
relevante para ele, em meio a um grande volume de informações presentes nos vídeos da plataforma YouTube.

\author{
Diálogo 2 (cont.): \\ (...) \\ [PE]: Pode ser áudio ou escrito \\ [PE]: Obrigada \\ [PE]: Só um minuto \\ [PE]: 1. Como você se interessou por esse jogo? \\ [PA]: Eu vi um vídeo no YouTube sobre o jogo e ele me interessou muito \\ [PE]: 2. O que você aprendeu jogando este jogo? \\ [PA]: Eu aprendi muito sobre geo política, política geral, estratégicas (tanto \\ econômicas \\ quanto militares), economia \\ [PE]: E sobre línguas, você escolheu Língua Estrangeira ou Língua \\ Portuguesa mesmo? \\ [PA]: No caso do jogo, a única língua disponível foi o inglês
}

Esses letramentos - baixar o jogo e selecionar conteúdo relevante - foram perpassados pela motivação do jogador ("me interessou muito") que se tornou o agente das ações que o levaram a alcançar o seu objetivo. Ele percorreu sozinho os caminhos que o levaram a adquirir tais letramentos, fato que lhe proporcionou uma sensação real de controle sobre o objeto de seu aprendizado e que raramente sentiria na escola (GEE, 2009).

O jogador encontrou o Geopolitical Simulator 4 na plataforma YouTube, onde participa, por meio de inscrição, de vários canais de jogadores de videogames que recomendam jogos e, também, que produzem tutoriais para níveis mais complexos de diversos/variados jogos. Uma característica comum entre os jogadores é estarem conectados em espaços de afinidade (GEE, 2003), onde comentam, opinam, dão sugestões e dicas sobre interesses em comum.

Na descrição, o participante usa o advérbio de intensidade "muito" para relacionar o conteúdo que aprendeu, conteúdo que se tivesse sido apresentado na escola, provavelmente teria sido apresentado de modo compartimentado. A esse respeito, Gee (2003) ressalta que situações de ensino-aprendizado 
acontecem, muitas vezes, em contextos informais de interação, mais especificamente, em espaços de afinidade. Nesse caso, o conhecimento aconteceu pela motivação causada pelo videogame. Há também de se considerar as diferentes configurações do espaço escolar e do espaço digital que oportunizam certas condições em um contexto que, até então, não são possíveis no outro.

Para atender ao primeiro objetivo deste estudo, perguntamos sobre a língua disponível pelo videogame. O participante então confirmou que o jogo só está disponível em inglês; a língua, nesse caso, foi usada como meio para se alcançar um objetivo: o de entender o videogame, para jogá-lo. Estudos sobre o inglês como meio de instrução apontam que essa abordagem tem, pelo menos, duas vantagens: o aprendizado de conteúdo diverso e o da língua inglesa (GALLOWAY, 2017). O objetivo do participante não era o de aprender a língua, mas o de poder fazer algo que exigia o conhecimento da língua. Logo, os dados nos mostraram que ele não utilizou um método de aprendizagem, mas uma estratégia para conseguir alcançar seu objetivo. Stern (1975) explica que os desafios estimulam a formulação de estratégias. Dentre elas, destacamos, para os propósitos deste estudo, as estratégias compensatórias, acionadas para superar lacunas de conhecimento e as estratégias metacognitivas, responsáveis pelo planejamento, gerenciamento, foco e avaliação da aprendizagem (OXFORD, 1990). Sugerimos que essas estratégias têm conexão com o desenvolvimento e as concepções de letramentos que discutimos na seção 2 deste artigo.

Quanto a outros fatores envolvidos na ação do participante, Gardner (1982) explica que esforço, desejo e afeto são considerados elementos da motivação. No caso dos videogames, podemos dizer que os elementos destacados por Gardner estão presentes no ato de jogar, uma vez que, "em um nível mais profundo, (...) o desafio e a aprendizagem são em grande parte aquilo que torna os videogames motivadores e divertidos" (GEE, 2009, p. 168). 
Outros estudos destacados por Gardner (1991 apud GEE 2009) mostram que, embora a aprendizagem escolar garanta o sucesso em testes, ela não garante a aplicação do conhecimento em situações reais. Quanto a jogar videogames, estudos com base na ciência cognitiva sugerem que essa prática pode incorporar princípios de aprendizagem (GEE, 2003, 2004), conforme apontamos previamente.

As inesperadas reações a cada jogada no Geopolitical Simulator 4, aliadas a um conteúdo que atrai o jogador (história, política, economia, etc.), pelo aspecto lúdico, dinamicidade e equivalência a um 'real' que não se pode experimentar no meio offline, mas cujo videogame propicia uma experiência corporificada, são as características que identificamos como motivadoras para a escolha deste jogo. Essas características estão em consonância com as funções da gamificação, sugeridas por Antin e Churchill (2011): definição de metas, instrução, reputação, status/afirmação e identificação de grupo. Mesmo quando se joga sozinho, o videogame exige tomada de posições antiéticas do jogador (algumas possibilidades são assassinar um adversário, financiar células violentas em protestos de rua e fraudar eleições), que podem fazer com que ele mesmo se identifique com um grupo (mesmo que anonimamente). Trata-se de uma experiência que proporciona uma reflexão sobre a construção de identidades dentro e fora do jogo, sobre modos de agir e se identificar com um ou outro grupo online e offline.

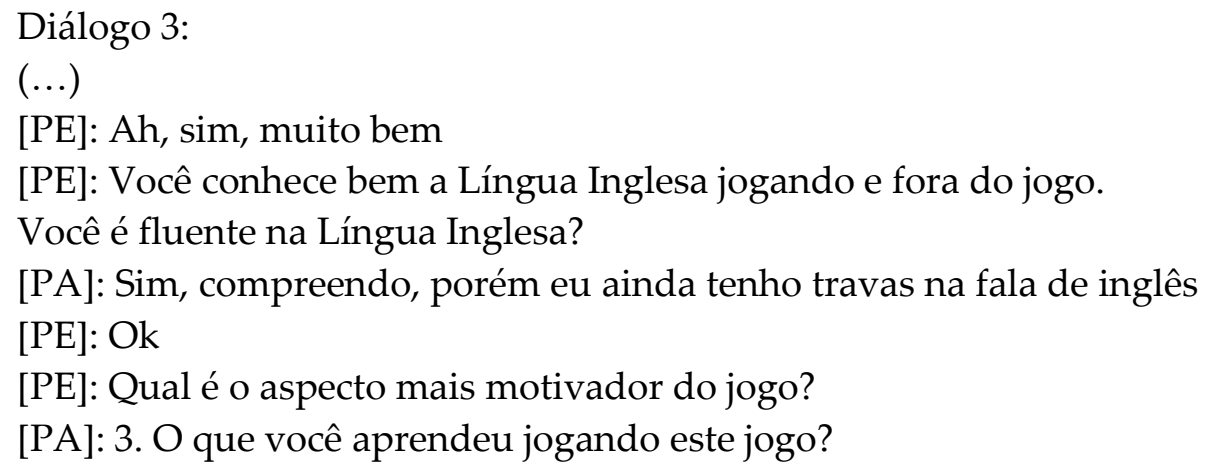


[PA]: O jogo em si não é tão motivador pela lentidão de progressão e os micro gerenciamentos

Na análise do diálogo três, constatamos que o jogador tem uma certa noção de suas habilidades na língua inglesa. Ele tem consciência de que entende a língua para jogar o videogame; ou seja, tem uma proficiência para aquela atividade, que não exige a oralidade. Embora não tenhamos perguntado, ele se adianta e nos explica sobre o seu status na língua inglesa: entende, mas tem "travas na fala". Tal status o permite alcançar o seu objetivo, ou seja, jogar.

Quando questionado sobre o aspecto motivador, o participante mostrouse crítico e expressou pontualmente o que considera negativo no videogame: "lentidão de progressão e os micros gerenciamentos". O domínio sobre a tecnologia e o conhecimento do passo a passo do videogame revelam capacidade de compreender as falhas e analisar criticamente algo que o motiva, mas que, não por essa razão, deixa de ter pontos negativos. Entendemos que para destacar os pontos positivos e negativos de qualquer atividade são necessários a prática e o conhecimento que se tem do produto, sob um ponto de vista relacional. Nesse caso, o participante demonstrou um letramento digital crítico específico na atividade de seu interesse e construído na sua relação com o jogo que pode leválo a dois caminhos: aceitar as regras ou buscar por propiciações que o permitam 'escapar' delas. $\mathrm{O}$ aceite ${ }^{22}$ é vinculado ao interesse por outras caraterísticas do videogame, conforme registrado no diálogo 4:

Diálogo 4:

(...)

[PE]: Mas, o que é que jogo faz com que você o jogue?

[PE]: Você conhece bem a Língua Inglesa jogando e fora do jogo.

Você é fluente na Língua Inglesa?

[PA]: Sim, compreendo, porém eu ainda tenho travas na fala de inglês

[PE]: O quão interessante e informativo e livre o jogo é

[PE]: Ok

${ }^{22} \mathrm{O}$ aceite não anula uma possível busca por propiciações de escape de regras. 
[PE]: Gostaria de ter essa experiência com o jogo, mas não consegui baixá-lo. Você poderia me ajudar?

[PA]: Jonas, agradeço pela sua disponibilidade em responder essas questões. Muito obrigada por contribuir no trabalho de Gamificação.

Se você me puder passar um site seguro para poder baixar o jogo, estarei na espera.

Obrigada! Boa noite.

Gee (2009) chama a atenção para a sensação de agência e de controle dada pelo jogo, e, ainda, para o papel de jogadores, uma vez que executam e tomam decisões. Sem essas ações, o jogo não acontece. Outra característica apontada por Gee (2009), e que está implícita na descrição “informativo” (diálogo 4), é que as informações estão contextualizadas, de modo hipermodal. Os assuntos declarados pelo participante no diálogo 1: "geopolítica, política geral, economia, estratégias econômicas e militares" são contextualizados e relacionados a ações, imagens e diálogos. Essa não é uma condição impossível na aprendizagem formal, mas, para que aconteça, é preciso mobilizar equipamentos e professores de diferentes áreas. Ademais, há, também, as condições contextuais, as quais apontamos previamente.

Ao informar e recomendar o programa operacional adequado para baixar o videogame, o jogador ressalta outro letramento digital. Tal conhecimento se dá pelo interesse em se relacionar com os objetos, em procurar caminhos e aprender sozinho ou em grupos de afinidades. Nossa experiência mostrou que a possibilidade de baixar o jogo, de modo 'livre', sem a necessidade de comprá-lo é uma propiciação que requer uma certa prática ${ }^{23}$.

23 No igg-games.com, é possível baixar versões antigas deste e de outros jogos. As versões atualizadas estão disponíveis em outros sites e são pagas. Para conseguir baixar uma versão antiga do Geopolitical Simulator 4, tivemos o auxílio de outro jogador adolescente, pois, geralmente, esses jogos vêm acompanhados por vírus que infectam o computador. Entretanto, tanto o participante deste estudo quanto o adolescente que nos auxiliou conseguem baixar os jogos, livres de vírus. Este é outro letramento digital que identificamos nesses sujeitos. 


\subsection{Possibilidades para o ensino formal}

A partir da análise dos dados, refletimos sobre caminhos possíveis de integração de características do videogame Geopolitical Simulator 4 na escola, tendo em vista a construção da ética e de sujeitos críticos em consonância com os letramentos digitais, na perspectiva sugerida por Lankshear e Knobel (2007) e Buzato (2009). Por exemplo, a análise mostrou que algumas possibilidades do líder de oposição no jogo são "financiar violentas células susceptíveis de intervir em confrontos de ruas, comprar urnas para ajudar a tomar as melhores decisões, repartir subornos, contratar detetives para obter informações sobre figuras influentes"24. Em paralelo aos acontecimentos do contexto físico, é possível promover debates sobre as consequências dessas ações no jogo e na vida real em uma perspectiva ética, situar os estudantes sobre a posição que ocupam no meio digital e no meio físico, e/ou incentivar o registro das consequências para os envolvidos da ação, dos dois lados. A divisão da sala em grupos e a proposição de apresentação dos resultados para professores, diretor, coordenadores, membros da comunidade, escolas de outros municípios, etc. poderia contar com premiação para as melhores propostas, bem como poderia acontecer a divulgação no canal da escola. Desse modo, essa ação aconteceria de forma dirigida, com vistas ao desenvolvimento da cidadania e a formação de cidadãos éticos e solidários (LIBÂNEO, 2003).

O recorte das possibilidades que guiou a reflexão sobre os modos que videogames podem contribuir com a educação formal é atravessado pelos pressupostos da linguística aplicada crítica, e embasado na perspectiva sociocultural sobre o desenvolvimento da linguagem, segundo Gebhard (1999, p. 544 apud PENNYCOOK, 2001, p. 144), que advoga que “(...) a origem e a estrutura da cognição estão enraizadas nas práticas sociais e culturais diárias das quais um

24 Disponível em: $<$ http://www.power-and-revolution.com/presentation.php?langue=pt $>$. 
indivíduo participa". As ações disponibilizadas pelo videogame (comprar urnas, repartir subornos, etc.) são ilegais e antiéticas, e por esses motivos proibidas no contexto físico. No entanto, acontecem e não são práticas incomuns, de acordo com os noticiários diários mundiais. No jogo, essas práticas são naturalizadas, materializadas na linguagem e permitidas, em troca de vantagens. Entendemos nessa premissa (ação ilícita $=$ vantagem) uma relação ativa com a realidade, baseados nos argumentos de Fairclough (1992), ao ponderar sobre o conceito de formação discursiva elaborado por Foucault (1972). Fairclough advoga que "a linguagem significa a realidade no sentido da construção de significado para ela, em vez de o discurso ter uma relação passiva com a realidade, com a linguagem meramente se referindo aos objetos, os quais são tidos como dados na realidade" (FAIRCLOUGH, 1992, p. 68-9). Partindo desse princípio e compartilhando a visão da escola como "espaços culturais estruturados que desempenham um papel na distribuição de práticas discursivas e a produção e reprodução de ordens sociais" (GEBHARD, 1999, p. 544 apud PENNYCOOK, 2001, p. 145), propomos a abordagem desse videogame em sala de aula, por meio de discussões orientadas, de forma não doutrinadora, mas problematizadora (MOITA LOPES, 2006), de modo que os estudantes possam refletir sobre os modos de se posicionar nos meios on e offline, em situações fictícias e reais.

Mais do que um estudo sobre os letramentos digitais necessários para jogar um videogame, este breve estudo nos fez refletir sobre as identidades das crianças e adolescentes que formamos na escola, no quanto temos de aprender com eles e no quanto mais podemos ensinar, se estivermos atentos às práticas de aprendizagem e aos discursos que acontecem em outros espaços. 


\section{CONSIDERAÇÕES FINAIS}

Este estudo foi motivado pela nossa percepção de que, cada vez mais, os videogames têm ganhado espaço na vida dos adolescentes. Diante dessa realidade, e como professores, sugerimos que estudos voltados ao conteúdo dos videogames, ao quanto eles podem ensinar e também do potencial que têm para o ensino e aprendizagem, podem contribuir para o estabelecimento de uma agenda híbrida que reconheça a autonomia do estudante em suas práticas não escolares e que seja capaz de conectar esses conhecimentos ao ensino formal.

Para nós, esta pesquisa foi relevante porque nos fez sair do nosso lugar de domínio e entrar em um mundo, até então, parcialmente desconhecido. Nos chamou a atenção para a riqueza do conhecimento compartilhado e do potencial dos nativos digitais ao nos despertar para as novidades e potencialidades de um videogame e, também, para o quanto esses jogos motivam e promovem o aprendizado periférico, por exemplo, o de uma língua estrangeira, usada como um meio para se atingir outros objetivos, que não necessariamente o de aprender uma língua. Como professores de língua inglesa, nos fez pensar sobre nossa concepção de aula de língua estrangeira e sobre os conteúdos selecionados para o ensino e aprendizado na escola. Por vezes, ficamos tão atrelados a regras e livros que esquecemos das outras possibilidades que estão cada vez mais disponíveis e que fazem, cada vez mais, parte do cotidiano dos alunos. Nesse sentido, a prática e conhecimento dos novos letramentos torna-se imprescindível para o professor de línguas e de todas as disciplinas, conforme propomos na discussão sobre os discursos naturalizados em videogames, tais como o Geopolitical Simulator 4.

Consideramos relevante propor reflexões acerca desse tema tão inovador e, ao mesmo tempo, necessário no meio educacional. Mais do que refletir, é preciso propor ações que encorajem o professor a se arriscar, se atualizar, se 
preparar para proporcionar não só ao aluno, mas a ele mesmo, oportunidades de reorganização de modelos que não se encaixam na nova dinâmica espaçotemporal estabelecida com o advento da internet. É tempo de rever conceitos, de desobstruir as veias do ensino pautado no mundo analógico... é tempo de se abrir ao novo, de forma criativa e responsável, em consonância com as necessidades e exigências das práticas desta nova era.

\section{REFERÊNCIAS}

ANTIN, J.; CHURCHILL, E. Badges in social media: A social psychological perspective. CHI 2011: Gamification Workshop Proceedings, 2011. Disponível em: <http://gamificationresearch.org/wp-content/uploads/2011/04/03-Antin-Churchill.pdf>. Acesso em: 18 jul. 2020.

BARTON, D. Literacy: an introduction to the ecology of written language. Oxford: Blackwell, 1994.

BARTON, D.; LEE, C. Linguagem online: textos e práticas digitais. 1ª ed. São Paulo: Parábola Editorial, 2015.

BORNFELD, B; RAFAELI, S. Gamifying with badges: a big data natural experience on stack exchange. First Monday, vol. 22, n. 6, 2017. Disponível em: $<$ https://firstmonday.org/ojs/index.php/fm/article/download/7299/6301>. Acesso em: 13 dez. 2019.

BUZATO, Marcelo E. K. Letramentos Digitais e Formação de Professores. In: III Congresso Ibero-Americano EducaRede: Educação, Internet e Oportunidades. Memorial da América Latina, São Paulo, BRASIL, 29 a 30 de maio de 2006. Disponível em: $<$ https://www.researchgate.net/publication/242229367_Letramentos_Digitais_e_Formac ao_de_Professores>. Acesso em: 15 nov. 2019.

BUZATO, Marcelo E. K. Letramento e inclusão: do estado-nação à era das TIC. Revista DELTA [online], v. 25, n. 1, p. 01-38, 2009. Disponível em: <https://doi.org/10.1590/S010244502009000100001>. Acesso em: 12 dez. 2019.

CASTELLS, M. A galáxia da internet: reflexões sobre a internet, os negócios e a sociedade. Tradução de Maria Luiza X. de A. Borges. Rio de Janeiro: Zahar, 2001.

DENZIN, N. K.; LINCOLN, Y. S. Introdução: a disciplina e a prática da pesquisa qualitativa. In: DENZIN, N. K.; LINCOLN, Y. S. (Orgs.). O planejamento da pesquisa qualitativa: teorias e abordagens. $2^{\underline{a}}$ ed. Porto Alegre: Artmed, 2006, p. 15-41.

DETERDING, S.; DIXON, D.; KHALED, R.; NACKE, L. From game design elements to gamefulness: defining "gamification". In: Proceedings of the 15th International Academic MindTrek Conference: Envisioning Future Media Environments (MindTrek '11), p. 09-15, 
$<$ https://www.researchgate.net/publication/230854710_From_Game_Design_Elements_ to_Gamefulness_Defining_Gamification>. Acesso em: 02 set. 2020.

DUDENEY, G.; HOCKY, N.; PEGRUM, M. Letramentos Digitais. 1aa ed. São Paulo: Parábola Editorial, 2016.

FAIRCLOUGH, N. Discourse and social change. Cambridge: Polity Press, 1992.

FESTINGER, L. A theory of social comparison processes. Human Relations, vol. 7, n. 2, p. 117-140, 1954.

FOUCAULT, M. The archeology of knowledge. Londres: Tavistock Publications, 1972.

GALLOWAY, N. How effective is English as a medium of instruction? British Council, 2017. Disponível em: <https://www.britishcouncil.org/voices-magazine/how-effectiveenglish-medium-instruction-emi>. Acesso em: 12 jul. 2020.

GARDNER, R. C. Language attitudes and language learning. In: BOUCHARD, R. E.; GILES, H. Attitudes toward language variation. London: Edward Arnold, 1982, p. 137-147.

GEBHARD, M. Debates in SLA studies: Redefining SLA as an institutional phenomenon. TESOL Quarterly, n. 33, 1999.

GEE, J. P. What Video Games Have to Teach Us About Learning and Literacy. New York: Palgrave/Macmillan, 2003.

GEE, J. P. Learning by design: games as learning machines. Interactional educational multimídia, n. 8, p. 15-23, 2004.

GEE, J. P. Bons videogames e boa aprendizagem. Tradução de Gilka Girardello. Revista Perspectiva, Florianópolis, v. 27, n. 1, p. 167-178, jan./jun. 2009. Disponível em: $<$ http://www.perspectiva.ufsc.br>. Acesso em: 20 abr. 2020.

HAMARI, J. Transforming homo economicus into homo ludens: A field experiment on gamification in a utilitarian peer-to-peer trading service. Electronic Commerce Research and Applications, v. 12, n. 4, p. 236-245, 2013. Disponível em: $<$ https://www.academia.edu/2448113/Transforming_Homo_Economicus_into_Homo_L udens_A_Field_Experiment_on_Gamification_in_A_Utilitarian_Peer_to_Peer_Trading _Service>. Acesso em: 12 jan. 2020.

LANKSHEAR, C.; KNOBEL, M. Sampling "the New" in New Literacies. In: KNOBEL, M.; LANKSHEAR, C. A new literacies sampler. New York: Peter Lang, 2007, p. 01-24.

LEFFA, V. J. Gamificação no ensino de línguas. Perspectiva, v. 38, n. 2, p. 01-14, 2020.

LEMKE, J. Travels in hypermodality. Visual Communication, vol. 1, n. 3, p. 299-325, 2002.

LIBÂNEO, J. C. Educação Escolar: políticas, estrutura e organização. São Paulo: Cortez, 2003.

MAGNANI, Luiz Henrique. Entre a liberdade e a coerção: videogames e construção de sentido. Ponto Urbe [Online], 2, 2008. Disponível em: $<$ https://journals.openedition.org/pontourbe/1917>. Acesso em: 02 set. 2020. 
MOITA LOPES, L. P. Linguística aplicada e vida contemporânea: problematização dos construtos que têm orientado a pesquisa. In: MOITA LOPES L. P. Por uma Lingüística Aplicada Indisciplinar. São Paulo: Parábola, 2006, p. 85-105.

OXFORD, R. Language learning strategies: what every teacher should know. New York: Newbury House, 1990.

PEGRUM, M. From Blogs to Bombs: The future of Digital Technologies in Education. Crawley: UWA Publishing, 2009.

PEGRUM, M. Modified, Multiplied, and (Re-) Mixed: Social Media and Digital Literacies. In: THOMAS, M. (Org.) Digital Education: Opportunities for Social Collaboration. Nova York: Palgrave Macmillan, 2011, p. 9-35.

PENNYCOOK, A. Critical Applied Linguistics: a critical introduction. Mahwah, N.J. and London: Lawrence Erlbaum Associates, Inc., 2001.

POWER \& REVOLUTION: GEOPOLITICAL SIMULATOR 4. Disponível em: $<$ http://www.power-and-revolution.com/presentation.php?langue=pt $>$. Acesso em: 22 nov. 2019.

PRENSKY, M. Use their tools, speak their language, p. 01-05, 2004. Disponível em: $<$ https://marcprensky.com/writing/Prensky-

Use_Their_Tools_Speak_Their_Language.pdf >. Acesso em: 09 set. 2020.

SEVERINO, A. J. Metodologia do trabalho científico. 23aㅡ ed. São Paulo: Cortez, 2007.

SMITH, A. From the feel of the page or the touch of a button: envisioning the role of digital technology in the English and language arts classroom. Spring, 2000. Disponível em: <http://www.msu.edu/ smitha62/computer.htm>. Acesso em: 20 dez. 2019.

SOUZA, V. V. S. Letramento digital e formação de professores. Revista Língua Escrita, n. 2, p. 55-69, dez. 2007.

STERN, H. H. What can we learn from the good language learner? Cambridge Modern Language Review, v. 34, n. 3, p. 304-318, 1975.

WARSCHAUER, M. Technology and social inclusion: rethinking the digital divide. Massachusetts: MIT Press, 2003.

XAVIER, A. C. Letramento digital: impacto das tecnologias na aprendizagem da Geração Y. Calidoscópio, v. 9, n. 1, 2011. Disponível em: $<$ http://revistas.unisinos.br/index.php/calidoscopio/article/view/748>. Acesso em: 10 jul. 2020.

YIN R. K. Estudo de caso: planejamento e métodos. $4^{\underline{a}}$ ed. Porto Alegre, RS: Bookman, 2010.

Nota do editor:

Artigo submetido para avaliação em: 10 de setembro de 2020.

Aprovado em sistema duplo cego em: 24 de fevereiro de 2021. 